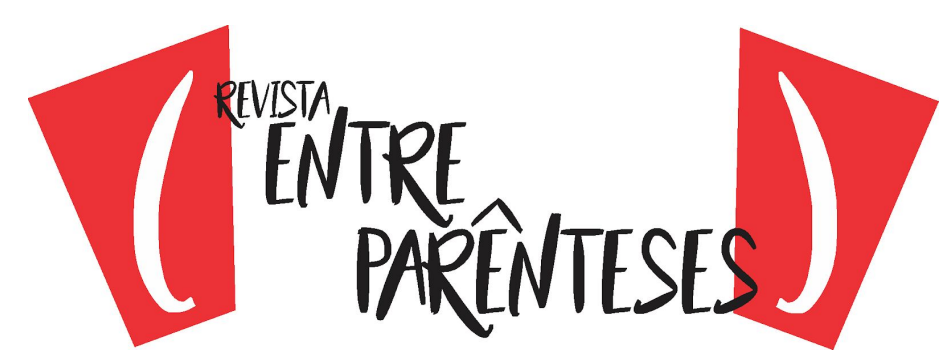

\title{
OS ARRANJOS DO REAL E DO FICCIONAL EM LITERATURA E HISTÓRIA
}

\author{
Ivanete da Silva Alves \\ Universidade Federal de Minas Gerais \\ (ivanety_23@hotmail.com)
}

\begin{abstract}
Resumo: Conceber a literatura como um objeto totalmente fantasioso e a história como a definição puramente do real é considerar que essas duas áreas são estruturas engessadas. No entanto, há aberturas no objeto literário e no historiográfico, e isso pode permitir possíveis sintonias entre a realidade e a ficção. Desse modo, pretende-se refletir sobre a articulação entre o real e o ficcional em literatura e história. Essa atividade pode ser positiva, visto que é uma oportunidade para se questionar as ideias essencialistas, pensamentos dicotômicos e reivindicar a perspectiva heterogênea que se faz relevante na contemporaneidade. Tal reflexão tem como sustentáculos as considerações de teóricos como Iser (2002); White (1994) e Derrida (2012; 2014), e conta com a análise dos romances "A selva", de Ferreira de Castro e "Cinzas do norte", de Milton Hatoum, a fim de examinar o diálogo entre os aspectos históricos e ficcionais presentes nas narrativas.
\end{abstract}

Palavras-chave: literatura; história; Cinzas do norte; A selva.

\section{THE ARRANGEMENTS OF THE REAL AND THE FICTIONAL IN LITERATURE AND HISTORY}

Abstract: To conceive of literature as a wholly fanciful object and history as the purely definition of the real is to consider these two areas to be rigid structures. However, there are openings in the literary and historiographical object, and this may allow for possible connexon between reality and fiction. Thus, we intend to reflect on the articulation between the real and the fictional in literature and history. This activity can be positive, since it is an opportunity to question the essentialist ideas, dichotomous thoughts and claim the heterogeneous perspective that is relevant in contemporary times. Such reflection is supported by the considerations of theorists such as Iser (2002); White (1994) and Derrida (2012; 2014), and relies on the analysis of the novels A selva, by Ferreira de Castro and Cinzas do norte, by Milton Hatoum, in order to examine the dialogue between historical and fictional aspects present in the narratives.

Keywords: literature; history; Cinzas do norte; A selva.

\section{LOS AJUSTES DE LO REAL Y LO FICCIONAL EN LITERATURA E HISTORIA}

Resumen: Concebir la literatura como un objeto totalmente fantasioso y la historia como la pura definición de la realidad es considerar estas dos áreas como estructuras de yeso. Sin embargo, hay aperturas en el objeto literario e historiográfico, y esto puede permitir posibles sintonizaciones entre la realidad y la ficción. Por lo tanto, tenemos la intención de reflexionar sobre la articulación entre lo real y lo ficticio en la literatura y la historia. Esta actividad puede ser positiva, ya que es una oportunidad para cuestionar las ideas esencialistas, los pensamientos dicotómicos y reclamar la perspectiva heterogénea que es relevante en los tiempos contemporáneos.Tal reflexión es apoyada por las consideraciones de teóricos como Iser (2002); White (1994) y Derrida (2012; 2014), y se basa en el análisis de las novelas $A$ selva, de Ferreira de Castro y Cinzas do norte, de Milton Hatoum, para examinar el diálogo entre aspectos históricos y ficticios presentes en las narraciones.

Palabras clave: literatura; historia; Cinzas do norte; A selva.

\footnotetext{
${ }^{1}$ Mestrado em Letras: Estudos Literários pela Universidade Federal de Minas Gerais.
} 


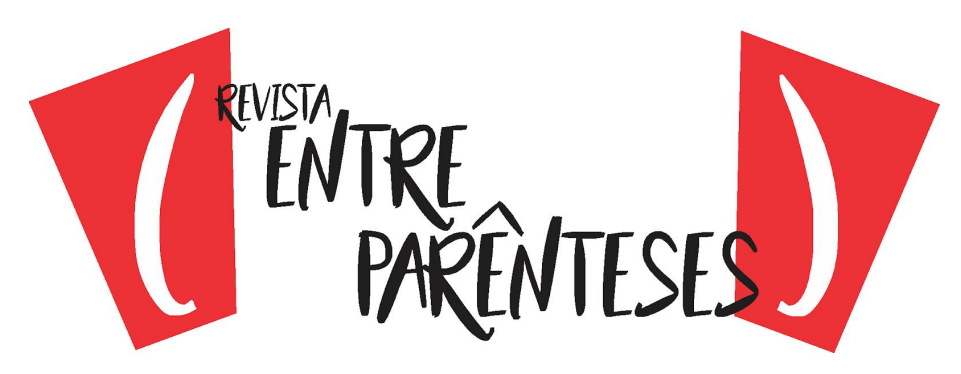

\section{Introdução}

Literatura e história são duas dimensões que carregam estereótipos, visto que há um entendimento de que a literatura é um produto da imaginação, fantasia e a história uma referência da realidade, experiência. Tidas em pólos opostos é como se houvesse uma fronteira bem delimitada entre essas duas dimensões que impede a interação entre elas. Assim, é visível uma organização binária que tenta delimitar o campo do verdadeiro e do falso, como se houvesse um essencialismo, uma identidade pura e autêntica nesses campos. No entanto, essa autenticidade é questionável. Bauman (1998), por exemplo, demonstra entender que ela é inexistente.

A noção de homogeneidade entorno do real e do ficcional é posta em xeque, tendo em vista que pode-se pensar que há uma interação entre os dois planos já que as fronteiras do espaço da realidade e da ficcionalidade não são tão rígidas, o que pode permitir trasbordamento de um lado para o outro levando a articulações. A articulação entre o âmbito da história e do literário é compreendida por Hatoum (2010). Nisso o escritor afirma diz que a literatura "fala basicamente da passagem do tempo, filtra uma experiência do autor, que é transferida para o narrador" (HATOUM, $2010 \mathrm{~s} / \mathrm{p}$ ). Tal pensamento expõe a estreita proximidade que pode haver entre a literatura e a historicidade e sustenta certa percepção do caráter heterogêneo de ambas.

Desse modo, a ideia sobre a relação entre a literatura e a história é interessante para ser debatida na contemporaneidade, já que em vez do isolamento disciplinar propõe-se o caminho entre fronteiras fluidas. Tal caminho pode ser uma oportunidade para tentar desestabilizar estereótipos e pensar o mundo a partir de uma perspectiva heterogênea. A percepção da heterogeneidade é relevante no cenário contemporâneo. Achugar diz "a heterogeneidade foi e é, de algum modo, 


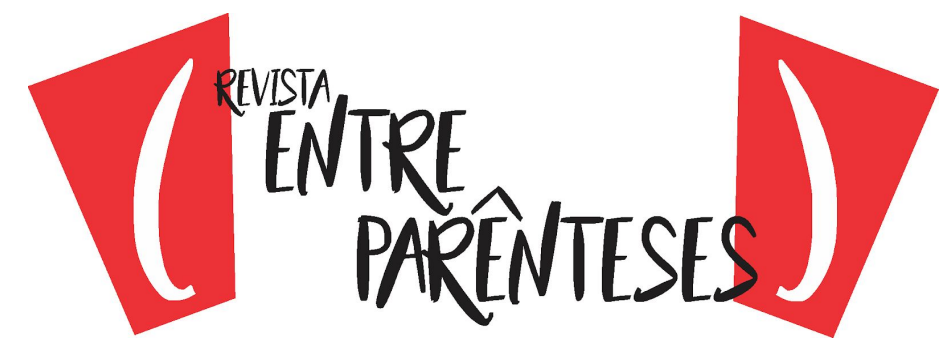

uma reivindicação e uma característica do discurso de resistência, diante de um projeto homogeneizante" (ACHUGAR 2006, p. 155).

Diante disso, pretende-se refletir sobre a relação entre a literatura e a história, tentando mostrar que ao invés de polarizadas há fronteiras fluidas que permitem diálogos entre elas. O trabalho tem como sustentáculos teóricos como Derrida $(2012$; 2014) e White (1994) por apresentarem percepções indispensáveis à reflexão proposta, e conta com análise de $A$ selva (1930), de Ferreira de Castro e Cinzas do norte (2005), de Milton Hatoum, momento em que se averigua a interação entre aspectos históricos e ficcionais encontrados nas narrativas.

O romance $A$ selva foi produzido pelo escritor português José Maria Ferreira de Castro após a experiência do autor na região amazônica, período em que viveu nos seringais. A obra narrada em terceira pessoa, conta a história de Alberto, jovem de vinte e seis anos, que ao chegar ao Pará para morar na casa de um tio foi mandado para o seringal Paraíso no rio Madeira estado do Amazonas. O personagem viveu a realidade semi-escravista imposta pelos seringalistas e presenciou cenas de dor e de selvageria.

Já Cinzas do norte é um romance do escritor brasileiro Milton Hatoum. $\mathrm{O}$ texto põe em pauta conflitos individuais, familiares e coletivos. $O$ narrador em primeira pessoa objetiva contar a história do protagonista Mundo (Raimundo). Mundo é filho de Jano (Trajano Matoso), empresário de origem portuguesa com Alícia (provavelmente mestiça). $O$ enredo focaliza a renúncia de Mundo à herança dos Matoso. A renúncia se deve ao fato, principalmente de que Mundo discorda dos valores ideológicos do pai, visto que Jano despreza a cultura local e apoia a Ditadura Militar.

\section{Dois planos num movimento relacional}

Para pensar a relação entre literatura e história a fim de examinar o diálogo dos aspectos históricos e ficcionais nas narrativas $A$ selva e Cinzas do norte 


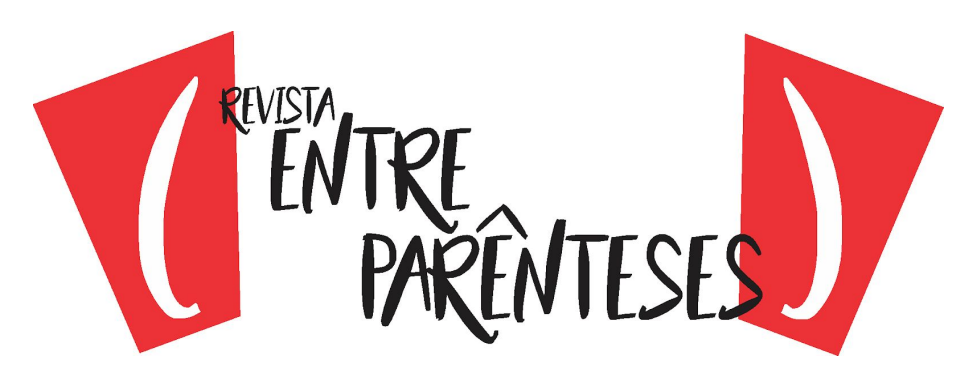

torna-se importante realizar uma breve reflexão conceitual acerca de cada um dos planos. Voltando-se à noção de história é notável a complexidade que carrega essa ciência. Santos (2000) comenta que essa palavra carrega sentido dúbio, explica que ela "pode ser utilizada para designar a experiência humana em sua dimensão temporal, no seu processo de contínua transformação. [...] A mesma, contudo, pode designar, não a experiência humana em si, mas o seu relato. Nesse caso, o termo história é sinônimo de historiografia". (SANTOS, 2000, p. 45). A afirmativa de Agamben sobre o assunto também é interessante. "Toda concepção histórica é sempre acompanhada de uma certa experiência do tempo que lhe está implícita, que a condiciona e que é preciso, portanto, trazer à luz" (AGAMBEN, 2005, p. 111).

A literatura também traz um caráter complexo. Obviamente não há conceitos estáticos sobre ela, mas há pensamentos em seu entorno que necessitam de destaque. Cevasco (2008, p. 147) diz que o significado pode mudar com o tempo, exemplificando que "na tradição britânica" literatura "significava, até o século XIX, um conjunto de escritos impressos. [...] No decorrer do século XIX, o sentido vai se especializando para significar escritos imaginativos de romances e poemas. [...] Progressivamente, cabe ao crítico decidir o que é literatura". A ideia de literatura também é pensada por Daniel-Henri Pageaux. "Para nós, a literatura define-se como o encontro de um projeto de escrita com a lógica de um imaginário". (PAGEAUX, 2011, p. 196). Derrida, ao ser questionado sobre o que é literatura, reflete,

A literatura como uma instituição histórica, com suas convenções, suas regras etc., mas também essa instituição da ficção que dá em princípio, o poder de dizer tudo, de se libertar das regras, deslocando-as, e, desse modo, instituindo, inventando e também suspeitando da diferença tradicional entre natureza e instituição, natureza e lei convencional, natureza e história (DERRIDA, 2014, p. $51)$.

As observações acima sobre literatura e história evidenciam a amplitude que abrangem cada uma dessas áreas. Isso leva a questionamentos acerca da 


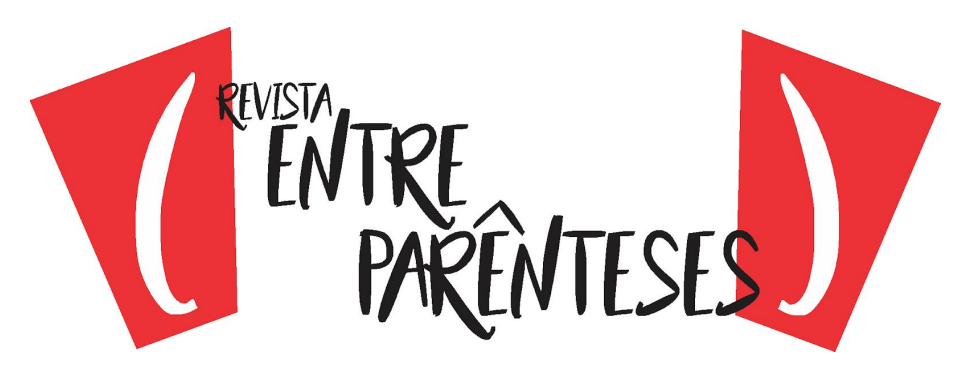

relação entre elas, pois há uma noção distorcida de que apenas a história traz a realidade, e a literatura uma falsidade, contudo essa lógica binária é questionável, uma vez que as duas dimensões possuem vínculos em comum. Santos menciona que há uma "íntima ligação entre o imaginário e o real" (SANTOS, 2000, p. 52). Tal entendimento também é mostrado por Hayden White (1994, p. 106) que afirma "os documentos históricos não são menos opacos do que os textos estudados pelo crítico literário. Tampouco é mais acessível o mundo figurado por esses documentos".

Se observarmos que a construção do texto literário envolve a relação com o tempo e a história dentro de um processo criativo, percebemos que a construção do texto histórico tem uma certa semelhança com a literatura. White (1994, p. 100) afirma que os historiadores objetivando realizar o "registro histórico" usam a "imaginação construtiva". O historiador com a situação histórica em mãos, dá um tratamento próximo ao literário à sua produção. White reflete como isso acontece.

O modo como uma determinada situação histórica deve ser configurada depende da sutileza com que o historiador harmoniza a estrutura específica de enredo com o conjunto de acontecimentos históricos aos quais deseja conferir um sentido particular. Trata-se essencialmente de uma operação literária, vale dizer, criadora de ficção. E chama-la assim não deprecia de forma alguma o status das narrativas históricas como fornecedoras de um tipo de conhecimento. (WHITE, 1994, p. 102).

A situação histórica é observada, selecionada e organizada pelo historiador por meio de um trabalho de memória. Por isso Le Goff (2003, p. 471) diz que a história cresce na memória. E rememorar, como nos lembra Ricoeur (2003, p. 7 ) é um luto porque há perdas. Não se pode guardar tudo. "Se somos incapazes de nos lembrar de tudo, somos ainda mais incapazes de tudo narrar" (RICOEUR, 2003, p. 7). Portanto, o historiador é alguém que filtra e dá forma. Assim, os acontecimentos históricos ganham conotação de estórias. 


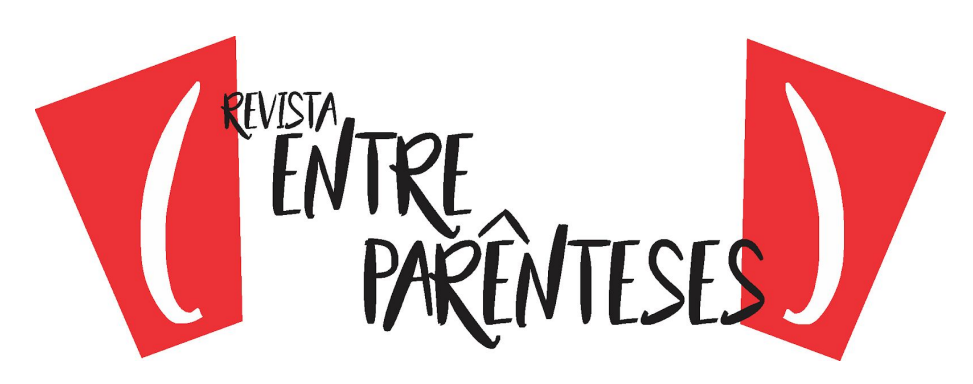

Os acontecimentos históricos são convertidos em estórias pela supressão ou subordinação de alguns deles e pelo realce de outros, por caracterização, repetição do motivo, variação do tom e do ponto de vista, estratégias descritivas alternativas e assim por diante - em suma, por todas as técnicas que normalmente se espera encontrar na urdidura do enredo de um romance ou de uma peça (WHITE, p. 100).

O modo como os registros históricos são feitos desestabiliza a noção de ambivalência entre realidade e fiç̧ão na historiografia, porque há uma afinidade ou estreitamento entre o real e o ficcional. Por isso White discorre, "há algo numa obra da história que não se pode negar, e esse elemento não-negável é a sua forma, a forma que é a ficção" (WHITE, 1994, p. 106). Ao invés de textos históricos puramente construídos com elementos do real, o que se tem são textos que estão no intermeio entre realidade e ficção. Contudo, "os historiadores talvez não gostem de pensar que suas obras são traduções do fato em ficções; mas este é um efeito das suas obras" (WHITE, 1994, p. 108).

Os historiadores, possivelmente almejam a transcrição do real, mas isso é uma impossibilidade. Não há como o historiador mostrar exatamente a realidade porque o real não pode ser transportado, apenas pode ser representado. A representação em si não é a realidade, ela é apenas uma espécie de imagem, e só se tem acesso ao real por meio dessa imagem. Paul Ricoeur afirma que "o passado está, por assim dizer, presente na imagem como signo da sua ausência, mas trata-se de uma ausência que, não estando mais, é tida como tendo estado" (RICOEUR, 2003, p. 2).

Vimos, portanto que a história dialoga com o fictício. Contudo, assim como a história não é isenta do teor ficcional, a ficção não se encontra distante da realidade. Essa compreensão foi averbada por Iser, o teórico afirma, "há no texto ficcional muita realidade" (Iser, 2002, p. 958). O texto literário transcende o real. É considerando a transcendência que Iser diz que o texto ficcional se refere a realidade "sem se esgotar nesta referência" (Iser, 2002, 859). Pensamento 


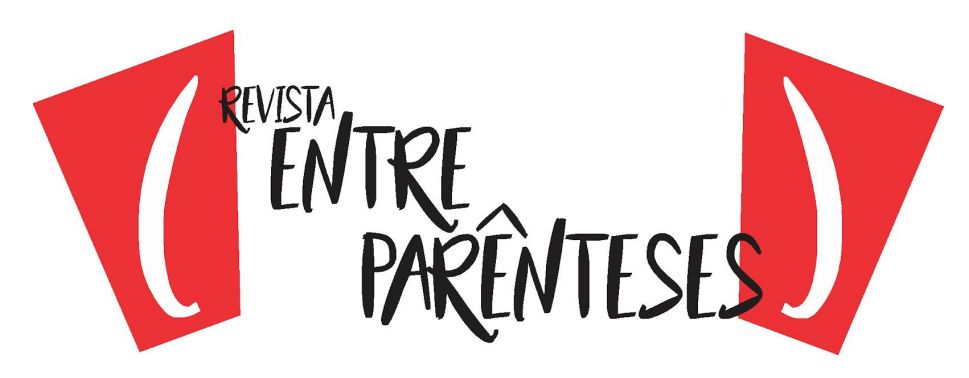

semelhante demonstra Milton Hatoum ao mencionar, "ela [a literatura] não é uma imitação do mundo, nem um retrato, nem um processo mimético do que a gente viveu, mas é a transcendência de tudo isso pela linguagem" (HATOUM, 2010). A relação da literatura com o mundo é pautado por Todorov (2009). Ele comenta, "como a filosofia e as ciências humanas, a literatura é pensamento e conhecimento do mundo psíquico e social em que vivemos. A realidade que a literatura aspira compreender é simplesmente [...] a experiência humana" (TODOROV, 2009, p. 77).

A realidade no texto literário de certo modo está vinculada na reflexão do escritor sobre o mundo e suas experiências. A partir dessa reflexão ele produz seu objeto. Nesse sentido a literatura pode ser compreendida como um modo alternativo de olhar para o mundo. Como afirma o próprio Hatoum, "a literatura é apenas um dos modos de você ver o mundo, de você transformar esse mundo através da linguagem" (HATOUM, 2010, p. 13). Então, o escritor usa a técnica literária para transcrever suas percepções.

\section{O real na tecitura de $A$ selva e Cinzas do norte}

Hayden White expõe que "pode-se comparar a história à literatura em razão do seu interesse mais no real que no possível" (WHITE, 1994, p. 105). O interesse da literatura pelo real pode ser notado na obra $A$ selva, do escritor Português José Maria Ferreira de Castro e em Cinzas do norte, do escritor brasileiro Milton Hatoum. As duas produções romanescas evidenciam as percepções dos escritores sobre um contexto social.

A selva tem uma perspectiva realista/naturalista, e segundo Cristóvão (1974, p. 21), o texto é um romance "social e de característica popular". Narrado em terceira pessoa, A selva tem como questão central a exposição da realidade do contexto social amazônico do início do século XX, já que a produção põe em pauta a realidade de sertanejos, principalmente do Ceará e do Maranhão, que se dirigiam à 


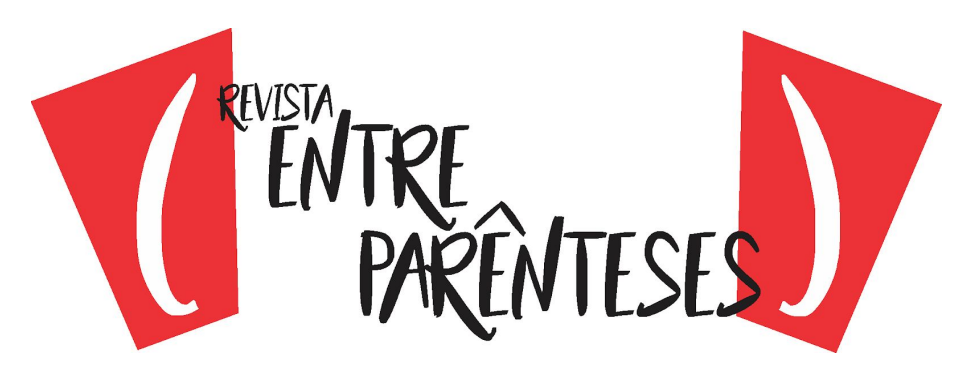

Amazônia para trabalhar na coleta do látex, nos diversos seringais espalhados por toda a floresta, no final do século XIX e início do XX. Sobre a trajetória e o trabalho dos seringueiros, Castro afirma que:

A luta de cearenses e maranhenses nas florestas da Amazônia é uma epopeia de que não ajuíza quem, no resto do mundo, se deixa conduzir, veloz e comodamente, num automóvel com rodas de borracha - da borracha que esses homens, humildemente, tiram à selva misteriosa e implacável. (CASTRO, 1972, p. 21)

Márcio Souza diz que "Ferreira de Castro, com $A$ selva, resumiu os trinta anos de loucuras nos seringais." (SOUZA, 1977, p. 123). Com a repercussão de seu livro na Europa o autor mostrou ao mundo a história de homens oprimidos pela natureza e envolvidos em um sistema semi escravista do qual o próprio autor também foi vítima. O texto revela a condição humana no ambiente da selva. Nele, "o homem é o seringueiro, o explorado, e a prosa amazônica torna-se insolente e denunciadora" (SOUZA, 1977, p. 127). A narrativa põe em pauta a opressão das pessoas, tanto pela natureza quanto pelo meio social. Desse modo, a obra parece estar vinculada a uma perspectiva em que o indivíduo é "condicionado pelos determinismos naturais ou explorado pelos outros homens" (CRISTÓVÃO, 1974, p. 21). Por isso, Fernando Cristóvão considera que o romance "se afirma como autenticamente literário por transfigurar a realidade ambiente no drama humano de proporções universais" (CRISTÓVÃO, 1974, p. 21).

O texto tem uma forte relação com a vida de Ferreira de Castro. A selva é uma obra produzida a partir da realidade vivida por seu autor no seringal Paraíso, localizado na região do rio Madeira, estado do Amazonas. Ele viveu a dura realidade nos seringais e deixa claro que quer mostrar o teor real desse meio. $O$ autor nunca escondeu a relação do surgimento dessa narrativa com os anos difíceis que passou no norte brasileiro. Essa relação é claramente explicitada no texto que antecede o romance: "Havia em mim o desejo de dar uma síntese de toda a selva do Amazonas e, não só por isso, mas pela força da própria experiência pessoal" 


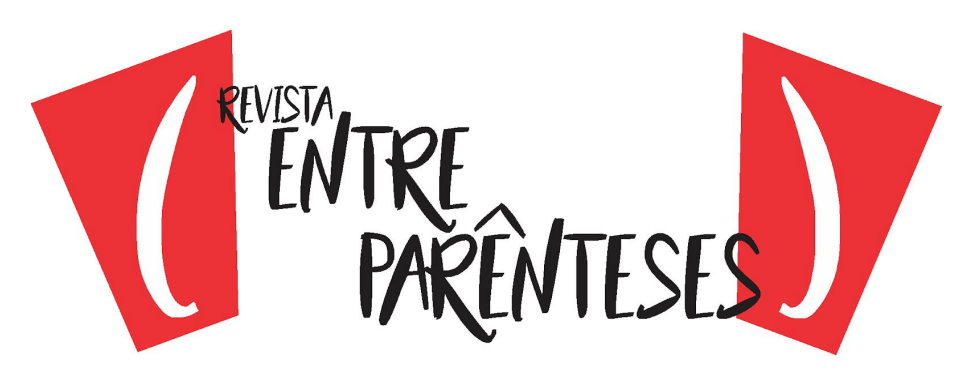

(CASTRO, 1972, p. 30). Isso é comentado por críticos como Lucilene Gomes Lima que observa, "ao escolher a Amazônia como espaço de representação de seu romance, Ferreira de Castro não o fez como um absentista, mas baseou-se na própria vivência de quatro anos num seringal" (LIMA, 2009, p. 112).

Foram quatro anos no seringal. $O$ escritor português nunca escondeu $O$ sofrimento vivido e presenciado na Amazônia: "Tremendas horas suportei no Brasil: primeiro no mundo elementar da floresta virgem, mais tarde em Belém do Pará, cromática, luminosa cidade, que uma vez projectada através dos nossos olhos, fica a residir, para sempre, na memória" (CASTRO, 2007, p. 23). Márcio Souza diz que Ferreira de Castro "experimentou ele mesmo, o destino de ser personagem" (SOUZA, 1977, p. 123).

Ferreira de Castro deixa transparecer que essa experiência gerou nele uma verdadeira necessidade de criar o romance, revelando que a obra vinha pagar uma espécie de dívida pessoal que ele tinha com a floresta e, sobretudo, com os aventureiros que iam para os seringais, desafiando a própria sorte.

\begin{abstract}
Eu devia este livro a essa majestade verde, soberba e enigmática, que é a selva amazônica, pelo muito que nela sofri durante os primeiros anos da minha adolescência e pela coragem que me deu para o resto da vida. E devia-o, sobretudo, aos anônimos desbravadores, que viriam a ser meus companheiros, meus irmãos, gente humilde que me antecedeu ou acompanhou na brenha, gente sem crônica definitiva, que à extração da borracha entregava a sua fome, a sua liberdade e a sua existência. Devia-lhes este livro, que constitui um pequeno capítulo da obra que há de registrar a tremenda caminhada dos deserdados através dos séculos, em busca de pão e de justiça (CASTRO, 1972, p. 21).
\end{abstract}

O escritor, ao basear-se em fatos históricos para tecer a fiç̧ão, parece querer realizar uma espécie de registro da vida no seringal e da exploração dos coletores de borracha. O tom documental do romance é um dos elementos que sustenta o desejo pela explanação da realidade. Com ela busca-se um efeito de veracidade, semelhante ao que sustentam as concepções realistas de literatura: "o 


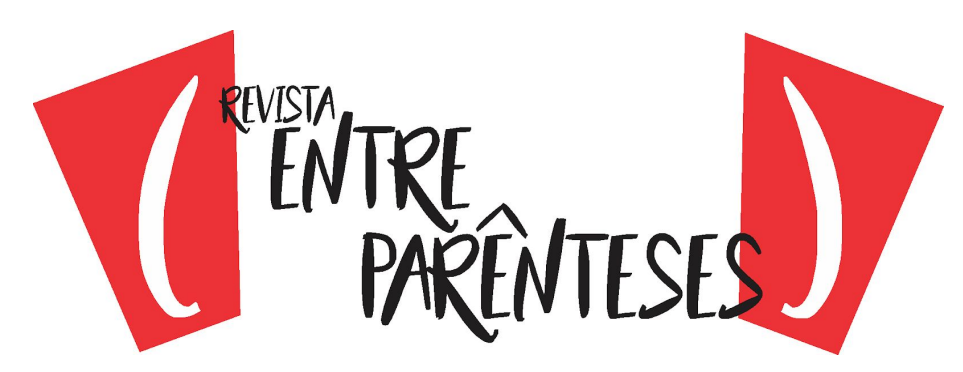

documental nos remete sempre à proximidade das coisas" (SOUZA, 1977, p. 110). Vale lembrar, no entanto, que o romance não consiste na transposição da realidade, por ser um texto ficcional. Juntamente com Roland Barthes (2004, 181-190), podemos considerar que ele apenas cria um "efeito de real", uma ilusão de realidade que é típica das obras pertencentes aos movimentos do Realismo e do Naturalismo.

Assim, o escritor português objetivou mostrar, por meio da ficção, uma "verdade" sobre a vida humana na selva, nesse período historicamente marcante para a região. Nessa empreitada, ele "dá conta de uma realidade que em si clama por justiça" (CRISTÓVÃO, 1974, p. 21). Souza observa ainda que o autor "escreveu o realismo do silêncio, sem reivindicações, recriando por escrito as torturas de sua adaptação" (SOUZA, 1977, p. 125). A perspectiva realista/naturalista da narrativa é claramente evidenciada, tanto por certas características, como a técnica de narração e a organização temporal do romance, quanto pela estrutura global da narrativa, construída para produzir no leitor um efeito de revelação, que desfaz suas ilusões quanto à realidade representada. O próprio romancista comenta sua busca pela veracidade.

Dir-se-ia que $A$ selva, drama dos homens perante as injustiças de outros homens e as violências da natureza, estava destinada a ser, desde o princípio ao fim, para o seu próprio autor, uma pequena história, uma pequena parcela da grande dor humana, dessa dor de que nenhum livro consegue dar senão uma pálida sugestão (CASTRO, 1972, p. 32).

Contudo, é muito importante observar que o texto castriano, apesar de ser resultado da experiência do autor, não é uma autobiografia. $A$ selva é um romance, um texto que se relaciona com a vida do escritor, mas que transcende a realidade vivida por ele e se apresenta para o leitor como uma obra ficcional. O próprio nome do protagonista e as significativas diferenças entre sua trajetória e a do autor sinalizam esse caráter ficcional, que implica na criação de um universo imaginário por meio da escrita, com um tempo, um espaço, um narrador e um conjunto de 


\section{("ifires}

personagens cuja realidade é constituída pela linguagem na qual a história é contada. Assim, os elementos da realidade são reelaborados, resultando numa obra que reflete sobre essa realidade, buscando se posicionar diante dela, mas que não corresponde integralmente aos acontecimentos e experiências vividos por Ferreira de Castro, em sua passagem pela Amazônia.

A reelaboração da realidade também é notada em Cinzas do norte, de Milton Hatoum. No texto é possível perceber que ele também tem um certo caráter autobiográfico, embora ele seja menos acentuado do que o que vimos em $A$ selva, de Ferreira de Castro. Mais interessante, talvez, seja perceber que a narrativa se refere a certas circunstâncias que foram compartilhadas por uma geração. Pois o romance tem como contexto o processo de mudanças vivido pela região, decorrente do projeto civilizatório que foi pensado para ela na segunda metade do século XX e, especialmente, o período da Ditatura Civil Militar implantada no Brasil em 1964. Em uma entrevista à revista Crioula, Milton Hatoum comentou sobre esse quadro histórico em que a obra se insere: "É importante até para contextualizar a narrativa. Faz parte também da minha vida, da minha geração, que vivenciou essa época, que cresceu durante o regime militar" (HATOUM, 2010).

Enfim, parece claro que o romance tem uma perspectiva geracional. Ele recria a história de pessoas que viveram em comum uma forte contradição entre a "desordem" política e social articulada a um discurso que pregava a "ordem": uma cidade tumultuada, caótica, mas inserida num processo de modernização, vinculado ao autoritarismo militar e estabelecido em todo o país. Então, a narrativa alude à realidade de uma geração amazônica e brasileira que passou por momentos de instabilidade e descrença no princípio democrático.

A associação do mundo ficcional à realidade vivida pelo escritor é um fato que já foi reafirmado por ele em várias ocasiões. Sempre que se posiciona a respeito de seus textos, Hatoum deixa claro o quanto as obras se relacionam com suas 


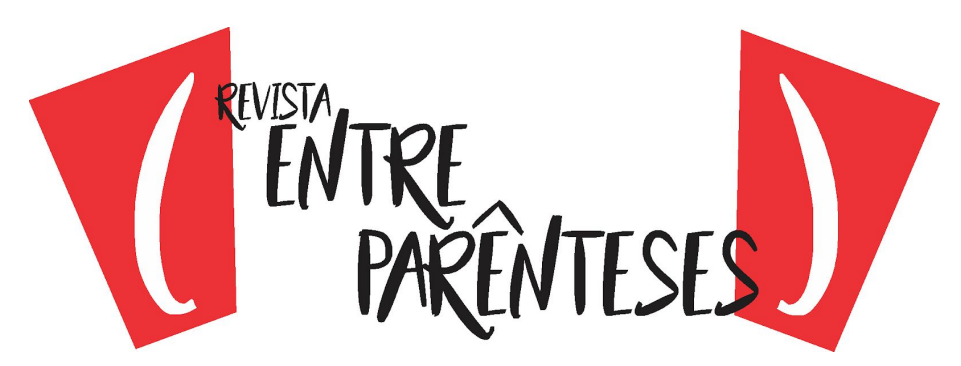

experiências. Um exemplo é a entrevista concedida à revista Digestivo cultural, em 2006, um ano após a publicação de Cinzas do norte:

Percebi que podia abordar questões a partir da minha própria experiência e das leituras. $E$ fiz isso sem censura, sem condescendência, usando recursos técnicos que aprendi com algumas obras. Tive a sorte de nascer e morar numa cidade portuária, onde não faltam novidades nem aventuras ou casos escabrosos. Além disso, os membros da minha tribo manauara, amigos, parentes e vizinhos não eram figuras de uma natureza-morta. Histórias que vinham de todos os lados, de minha casa, da vizinhança, do porto, dos bordéis-balneários e até da casa do arcebispo. Quando penso na minha infância e juventude, percebo que foi a época em que vivi com mais intensidade, dia e noite. Havia tudo, inúmeras peripécias e também a política, pois meus tios participavam da vida política, que era mais um assunto doméstico. Aos 15 anos saí sozinho e fui morar em Brasília, isso em 1968. E depois morei em São Paulo e fora do Brasil, o que foi importante para minha formação. Chegou um momento em que fiz uma pausa e comecei a escrever sobre esse passado. Mas não queria escrever qualquer coisa, me debrucei no trabalho, na forma do texto, na construção dos personagens. (HATOUM, 2006b)

Narrado em terceira pessoa "Cinzas do norte se reporta aos anos de chumbo, um momento histórico em que não havia espaço para a expressão da alteridade" (CARREIRA, 2009, p. 2). A obra faz várias referências a esse contexto, como ao apresentar uma cidade sob o poder das Forças Armadas e marcada pela miséria. Vieira comenta sobre esse pano de fundo histórico e social da obra: "O mundo narrativo aparece em primeiro plano com o espaço, uma Manaus decadente e uma natureza misteriosa, no fundo" (VIEIRA, 2007, p. 172). Contudo, apesar do aspecto arruinado, a cidade está em processo de modernização.

A obra retrata as transformações ocorridas em Manaus e na Amazônia. Slater descreve assim a Manaus que serve de cenário ao romance: "um conjunto de fábricas sem árvores, hotéis e lojas de importação que revelam uma mistura de culturas que florescem nas ruas enlameadas dos fundos e nas novas estradas de 


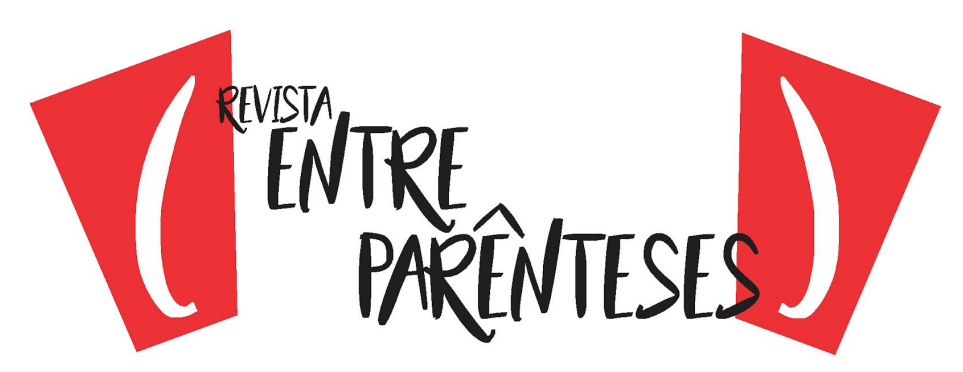

concreto" (SLATER, 2007, p. 355). Esse panorama também é comentado por Tânia Pellegrini, ao refletir sobre os principais romances hatounianos:

Avulta também o tempo da história brasileira, disfarçado como tema secundário: o do processo de modernização do país, com ecos específicos na região norte, que talvez mais do que outros lugares, revela com crueza as marcas da convivência de progresso e atraso, de avanço e estagnação, de permanência e mudança. (PELLEGRINI, 2007, p. 100)

O texto põe em pauta o projeto colonialista na Amazônia e a ideologia dominante sobre os indígenas. No espaço da narrativa os dogmas civilizatórios de ordem e progresso foram implantados e os nativos são vistos de modo pejorativo, por não se curvarem totalmente às ideias colonialistas. A postura do romancista se aproxima do pensamento de Galeano. O teórico ao falar sobre os índios diz que eles "participam como vítimas, de uma ordem econômico-social em que desempenham o duro papel de os mais explorados entre os explorados" (GALEANO, 2015, p. 79).

A obra também dá relevo às ideias totalitárias do governo ditatorial. Os centros de ensino destacados na narrativa são uns dos lugares representantes da ideia de ordem e regramento, conotando a estabilidade e a disciplina social. Por isso Carreira afirma que, "em Cinzas do norte, a escola reproduz a mesma violência do Estado" (CARREIRA, 2009, p. 7).

Vale observar que o romance de Hatoum expõe um olhar para o mundo sob a ótica da multiplicidade ao revelar a heterogeneidade do espaço narrativo. $O$ aspecto heterogêneo da cidade se reflete de modo acentuado no espaço ficcional de Cinzas do norte, uma vez que a história narrada nesse texto se passa predominantemente no ambiente urbano. A selva e o meio rural aparecem com bem menos destaque. O próprio escritor fala a respeito do espaço de suas narrativas: "O norte dos meus romances é uma cidade, Manaus, que mantém vínculos fortes com o interior do Amazonas" (HATOUM, 2006b). Em entrevista para um grupo acadêmico 


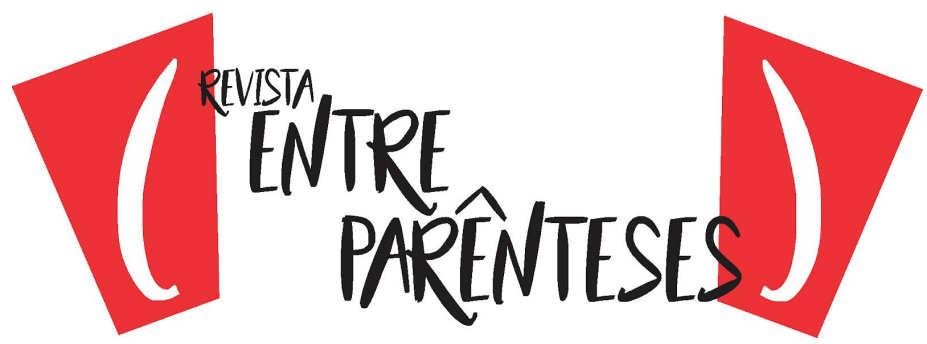

da Universidade Estadual do Norte do Paraná o escritor dá uma explicação sobre essa opção:

\begin{abstract}
Porque eu nasci em Manaus, eu sou de lá, nasci numa família amazonense, de imigrantes, e a minha infância, também minha primeira juventude, foram passadas em Manaus. [...] Então, muita coisa do meu primeiro romance, de todos na verdade, tem a ver com esse mundo, com esse pequeno mundo de Manaus e um pouco também com o interior do Amazonas que eu conheço, vamos dizer, profundamente. (HATOUM, 2016, p. 131)
\end{abstract}

A obra hatouniana mostra uma Manaus multifacetada. Nesse contexto presencia-se a miséria e a precarização da vida, em decorrência das ações excludentes realizadas em nome do progresso. Como comenta o próprio Hatoum, "na cidade planejada segundo um ideário burguês muito mal aclimatado no equador, é preciso pensar em formas de isolamento dos excluídos" (HATOUM, 2006a, p. 55).

No cenário narrado, os indivíduos pobres, como mendigos, vendedores ambulantes, indígenas e prostitutas, entre outros, estão à margem do processo modernizador, riscados das políticas públicas. O próprio Hatoum, falando sobre Manaus, afirma que, "na nova cidade, os índios e imigrantes pobres tornam-se trabalhadores urbanos, homens e mulheres excluídos de um projeto em que só há lugar para as elites e uma classe média incipiente" (HATOUM, 2006a, 55).

A pluralidade em Manaus também é exposta ao focalizar diferentes perspectivas culturais presentes na Amazônia principalmente por meio da presença estrangeira. O reconhecimento da importância dos processos migratórios é relevante para os questionamentos sobre as imagens essencialistas da Amazônia porque evidencia o caráter eminentemente plural e multifacetado da região.

Assim, a produção hatouniana converge com uma perspectiva contemporânea, que desacredita das essências e considera a importância de se levar em conta os processos históricos, sociais, políticos e culturais nas maneiras de se conceber a Amazônia. Contudo, o romance não se detém exclusivamente no 


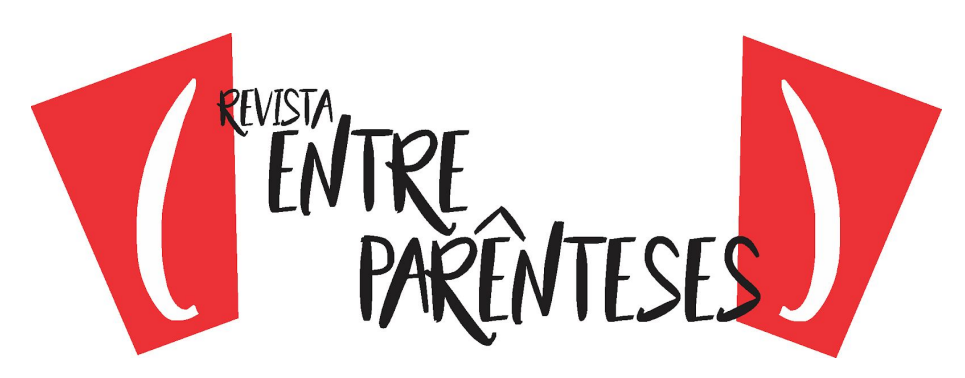

plano regional, uma vez que alude a conflitos humanos de maior abrangência, como os que se referem às ações imperialistas e ditatoriais que se repetem em diferentes lugares mundo.

Portanto, o texto de Milton Hatoum, assim como a romance de Ferreira de Castro, expõe a relação entre realidade e ficção. O escritor português com um teor mais autobiográfico e o escritor brasileiro com um tom mais geracional mostram a transcendência do real na criação do objeto ficcional. Então, podemos concordar que "ficção não é sinônimo de falsidade, mas de suspensão do limite que separa os conceitos de falso e de verdadeiro" (SANTOS; OLIVEIRA, 2001, p. 19).

\section{Considerações finais}

A reflexão desenvolvida aqui, que contou com a análise dos romances $A$ selva e Cinzas do norte, tentou mostrar que a realidade e ficção se aproximam na historiografia e na literatura, portanto, "desaparece assim a oposição entre ficção e realidade" (ISER, 2002, p. 960). A pouca rigidez entre suas fronteiras permite uma certa interação que pode ser positiva tanto para a história quanto para a literatura. White menciona que "a história, enquanto disciplina vai mal atualmente porque perdeu de vistas as suas origens na imaginação literária" (WHITE, p. 106). Já a literatura sempre ganha com a abertura à interdisciplinaridade. Ao falar de Literatura Comparada Carvalhal (2006) diz que "Os estudos interdisciplinares em Literatura comparada instigam a uma ampliação dos campos de pesquisa e à aquisição de competências" (CARVALHAL, 2006, p. 74).

O entendimento de que o ficcional e o real possuem uma atividade relacional entre história e literatura pode contribuir para a quebra de perspectivas essencialistas, pois claramente nenhuma dessas duas dimensões repousam em uma essência. Cabe mencionar que o fato de a literatura não ter um caráter essencialista possibilita a ela a articulação com diferentes discurso como o 


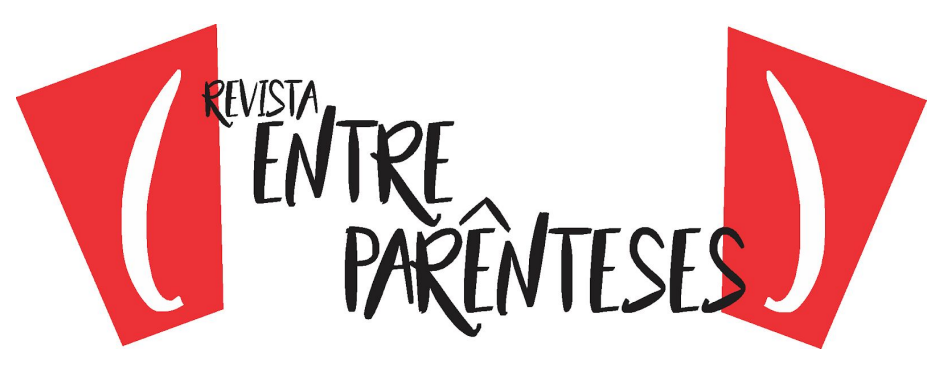

historiográfico. Derrida afirma que "é sempre possível reinscrever no espaço literário qualquer enunciado - um artigo de jornal, um teorema científico, um fragmento de conversa" [...] É sempre possível inscrever na literatura algo que não fora originalmente destinado para ser literário" (DERRIDA, 2014, p. 65).

Por fim, o estudo acerca da relação entre literatura e história pode ser favorável para se pensar na heterogeneidade. A ideia do heterogêneo é positiva pois fragiliza a noção de pureza que segrega o meio social e cultural. Desse modo, o discurso entorno da heterogeneidade é bastante relevante na contemporaneidade. Canclini afirma que "reivindicar a heterogeneidade e a possibilidade de múltiplas hibridações é um primeiro movimento político para que o mundo não fique preso sob a lógica homogeneizadora" (CANCLINI, 2015, p. 9).

\section{Referências}

ACHUGAR, Hugo. Planetas sem boca: estudos efêmeros sobre arte, literatura e cultura. Tradução: Lyslei Nascimento. Belo Horizonte: UFMG, 2006.

AGAMBEN, Giorgio. Infância e história: destruição da experiência e origem da história. Tradução: Henrique Burigo. Belo Horizonte: Ed. UFMG, 2005.

BARTHES, Roland. O rumor da língua. Tradução: Mario Laranjeira. São Paulo: Martins Fontes, 2004.

BAUMAN, Zygmunt. O mal-estar da pós-modernidade. Tradução: Mauro Gama, Cláudia Martinelli Gama. Rio de Janeiro: Zahar, 1998.

CANCLINI, Néstor García. Culturas híbridas. Tradução. Heloísa Pezza Cintrão e Ana Regina Lessa. São Paulo: Editora da USP, 2015.

CARREIRA, Shirley de Souza Gomes. Diferenças e alteridade em Cinzas do Norte, de Milton Hatoum. Vertentes, São João Del-rei, n.34, p.1-12, 2009. Disponível em: $<$ https://ufsj.edu.br/portal-repositorio/File/Vertentes34/Shirley Carreira.pdf $>$. Acesso em: 30 jul., 2017.

CASTRO, José Maria Ferreira de. A selva. São Paulo: Verbo Ltda, 1972. 


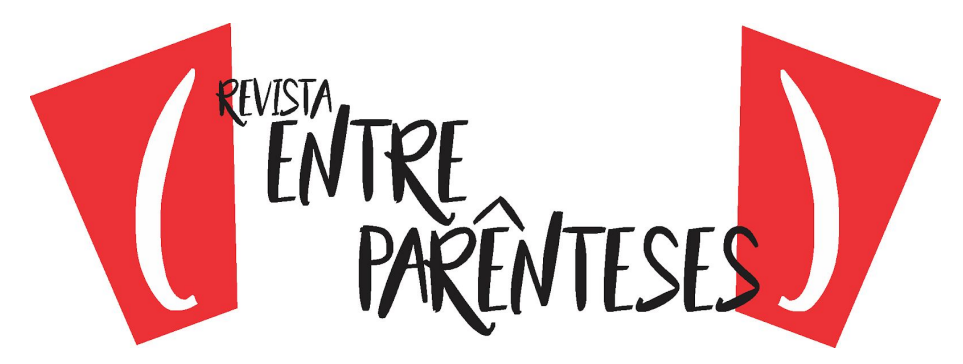

CASTRO, Ferreira de. Arquivo: Pequena história de <<Emigrantes>>. Castriana: Estudos sobre Ferreira de Castro e a sua Geração, Ossela, n. 3, p.61-104, 2007. Tradução: Ivone Bastos Ferreira. Disponível em: < http://www.ceferreiradecastro.org/pdf/castriana3.pdf > Acesso em: 01 mar., 2018.

CARVALHAL, Tania Franco. Literatura comparada. 4 ed.. São Paulo: Ática, 2006.

CEVASCO, Maria Elisa. Dez lições sobre estudos culturais. 2. ed. São Paulo: Boitempo, 2008.

CRISTÓVÃO, Fernando. Ferreira de Castro e a literatura brasileira. Colóquio Letras. Inquérito: o futuro do Português como língua literária em África. Homenagem a Ferreira de Castro. № 21, p. 20-22, setembro de 1974. Disponível em: $<$ http://coloquio.gulbenkian. $\mathrm{pt} / \mathrm{bib} /$ sirius.exe/issueContentDisplay? $\mathrm{n}=21 \& \mathrm{p}=20 \& \mathrm{o}=\mathrm{r}>$. Acesso em 01 mar., 2018.

DERRIDA, Jacques. Pensar em não ver: escritos sobre as artes do visível (1979-2004). Tradução: Marcelo Jacques de Moraes. Florianópolis: Ed. da UFSC, 2012.

Essa estranha instituição chamada literatura. Tradução: Dias Esqueda. Belo Horizonte: Editora UFMG, 2014.

GALEANO, Eduardo. As veias abertas da América Latina. Tradução: Sergio Faraco. Porto Alegre: L\&PM Pocket, 2015.

GONÇALVES, Carlos Walter Porto. Amazônia, Amazônias. Segunda edição. São Paulo: Contexto, 2005.

HATOUM, Milton. Cinzas do norte. São Paulo: Companhia das Letras, 2005.

Amazonas capital Manaus. In: NUNES, Benedito; HATOUM, Milton. Crônica de duas cidades - Belém e Manaus. Belém: Secult, 2006a, p. 49-70.

Milton Hatoum. Digestivo cultural, São Paulo, 1 maio 2006b s/p. Entrevista concedida a Julio Daio Borges. Disponível em: <https://www.digestivocultural .com/entrevistas/entrevista.asp?codigo=1\&titulo=Milton_Hatoum>. Acesso em: 05 abr., 2018.

Entrevista com Milton Hatoum. Claraboia, Jacarezinho, v.5, p. 129-135, jan./junh., 2016. Entrevista concedida a Danivia Cassiano Feliciano e Letícia Barboza.

Disponível

em: 


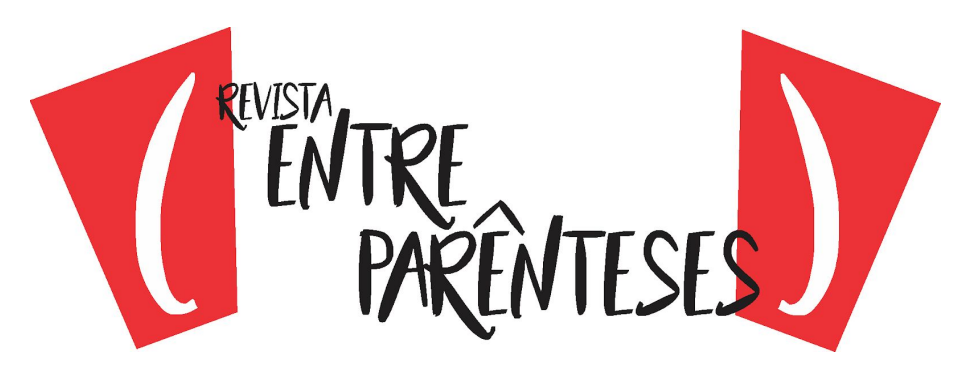

<http://seer.uenp.edu.br/index.php/claraboia/article/viewFile/ 762/pdf_67>. Acesso em: 10 abr., 2018.

Milton Hatoum: "Não há tantos tradutores de literaturas de língua portuguesa”. Revista Crioula, São Paulo, n. 7, maio de 2010. Entrevista concedida a Maged El Gebaly. Disponível em: <http://www.journals.usp.br/crioula/article/viewFile/ 55258/ 58887>. Acesso em: 05 abr., 2018.

ISER, Wolfgang. Os atos de fingir ou o que é fictício no texto ficcional. In; LIMA, Luiz Costa (Org.). Teoria da literatura em suas fontes. vol. 2. 3 ed. Rio de Janeiro: Civilização brasileira, 2002.

LE GOFF, Jacques. História e memória. Tradução: Bernardo Leitão [et. al.]. 5 ed. Campinas: Editora Unicamp, 2003.

LIMA, Lucilene Gomes. Ficções do ciclo da borracha: A selva, Beiradão e O amante das amazonas. Manaus: Editora da universidade federal do Amazonas, 2009.

PAGEAUX, D. Musas na encruzilhada: ensaios de literatura comparada. São Paulo: Hucitec; Santa Maria: UFSM; Frederico Westphalen: URI. 2011.

PELLEGRINI, Tânia. Milton Hatoum e o regionalismo revisitado. In: CRISTO, Maria da Luz pinheiro (Org.) Arquitetura da memória: ensaios sobre romances Dois irmãos, Relato de um certo oriente e Cinzas do norte de Milton Hatoum. Manaus: Editora da Universidade Federal do Amazonas/UNINORTE, 2007, p. 98-118.

RICOEUR, Paul. A memória, a história o esquecimento. Tradução: Alain François [et al.]. Campinas: Editora da Unicamp, 2007.

SANTOS, Luis Alberto Brandão. Literatura e história: convergência de possíveis. In: BOECHAT, Maria Cecília Bruzzi e outros. Romance histórico: recorrência e transformações. Belo Horizonte, FALE/UFMG, 2000.

SANTOS, Luis Alberto Brandão; OLIVEIRA, Silvana Maria Pessôa de. Sujeito, tempo e espaço ficcionais: introdução à teoria da literatura. São Paulo: Martins Fontes, 2001.

SLATER, Candace. Resenha dois irmãos. Tradução: Ana Maria Furtado. In: CRISTO, Maria da Luz pinheiro (Org.) Arquitetura da memória: ensaios sobre romances Dois irmãos, Relato de um certo oriente e Cinzas do norte de Milton 


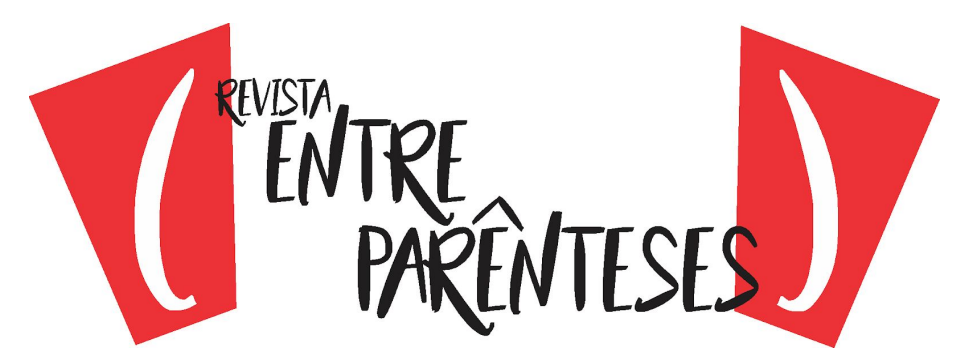

Hatoum. Manaus: Editora da Universidade Federal do Amazonas/UNINORTE, 2007, p. 352-355.

SOUZA, Márcio. A expressão amazonense: do colonialismo ao neocolonialismo. São Paulo: Alfa-Omega, 1977.

TODOROV, Tzvetan. A literatura em perigo. Tradução: Caio Meira. Rio de Janeiro, DIFEL, 2009.

VIEIRA, Estela J. Milton Hatoum e a representação do exótico e do imigrante. In: CRISTO, Maria da Luz Pinheiro (Org.). Arquitetura da memória: ensaios sobre romances Dois irmãos, Relato de um certo oriente e Cinzas do norte de Milton Hatoum. Manaus: Editora da Universidade Federal do Amazonas/UNINORTE, 2007. p. 171-178.

WHITE, Hayden. O texto histórico como artefato literário. In: WHITE, Hayden. Trópicos do discurso: ensaios sobre a crítica da cultura. Trad. Alípio Correia de franca Neto. São Paulo: Editora da Universidade de São Paulo, 1994, p. 97-116.

Recebido em: 08/10/2019

Aprovado em: 27/01/2020 